\title{
Long Term Treatment of Intractable Reflex Sympathetic Dystrophy With Intrathecal Morphine
}

\author{
W.J. Becker, D.P. Ablett, C.J. Harris and O.N. Dold
}

\begin{abstract}
Background: Some patients with reflex sympathetic dystrophy (RD) develop intractable symptoms unresponsive to conventional therapy. Recently, intrathecal morphine therapy has been used with some success in such patients. Methods: The clinical course of two patients with intractable reflex sympathetic dystrophy (RSD) is described. Both patients developed intractable leg pain, swelling and autonomic changes after a leg injury. Numerous medical treatments and surgical sympathectomies failed to provide long term relief. Results: Relatively satisfactory symptom control was achieved only with the use of long term intrathecal morphine therapy delivered by subcutaneously implanted infusion pumps. Exacerbations of the RSD continued to occur, at times in association with further leg trauma, but these could be controlled by a temporary escalation of the intrathecal morphine dose. Complications of morphine therapy were relatively minor. A red rash appearing over the pump site was the first sign that a drug catheter break had occurred, necessitating surgical catheter revision. Conclusion: Long term intrathecal morphine therapy is a useful treatment option for patients with intractable severe RSD who have failed other therapies and remain markedly disabled.
\end{abstract}

RÉSUMÉ: Administration à long terme de morphine intrathécale dans la dystrophie sympathique réflexe réfractaire au traitement. Introduction: Certains patients atteints de dystrophie sympathique réflexe (DSR) développent des symptômes réfractaires au traitement conventionnel. Depuis peu, l'administration de morphine intrathécale a été utilisée avec un certain succès chez ces patients. Méthodes: Nous décrivons l'évolution clinique de deux patients atteints de DSR réfractaire au traitement. Les deux patients avaient développé des douleurs réfractaires au membre inférieur, de l'oedème et des changements anatomiques après une blessure à la jambe. Plusieurs traitements médicaux ainsi que la sympathectomie ont échoué. Résultats: Un contrôle relativement satisfaisant des symptômes n'a été obtenu qu'avec l'administration à long terme de morphine intrathécale au moyen d'une pompe sous-cutanée. Les périodes d'exacerbation de la DSR, parfois associées à un nouveau traumatisme au niveau du membre inférieur, ont pu être contrôlées en augmentant temporairement la posologie. Les complications de l'administration de morphine ont été relativement mineures. L'apparition d'un érythème cutané au site de la pompe était le premier indice d'un bris du cathéter nécessitant une révision chirurgicale. Conclusion: L'adininistration intrathécale de morphine à long terme est une option thérapeutique utile chez les patients présentant une DSR sévère réfractaire au traitement et qui demeurent gravement incapacités.

Can. J. Neurol. Sci. 1995; 22: 153-159

Reflex sympathetic dystrophy (RSD) is characterized by diffuse burning pain, allodynia (pain on light touch) and autonomic dysfunction with swelling, temperature change, and redness or cyanotic mottling. It usually develops in a limb after a relatively minor injury.'

Three stages of RSD are recognized. Stage 1 is characterized by severe burning pain greater than that to be expected from the injury. The limb may show increased warmth, and swelling is present. By the time the second stage is reached, the limb is usually cold, the edema is now said to be "brawny" in nature, and the skin often shows a glazed appearance with reduced hair growth and brittle nails. Continuous burning pain continues. Stage 3 typically shows progression of the trophic changes with marked subcutaneous atrophy, muscle wasting, and tendon and joint contractures. Stage 1 may last as long as six months, and stage 2 up to two years post-injury, but these stages are not always distinct in a given patient, and their duration is very variable.

The pathogenesis of RSD is poorly understood, and the treatment is controversial.2 It appears that early mobilization and physical therapy are crucial to a successful outcome, but this is often difficult as the extreme pain and swelling may make manipulation and use of the limb impossible, despite the use of analgesics. Regional sympathetic blocks may provide temporary relief in many patients, and allow physical therapy to be given. If this does not provide a satisfactory resolution to the patient's

From the Department of Clinical Neurosciences. The University of Calgary and The Calgary General Hospital, Calgary.

RECEIVED JULY 28, 1994. ACCEPTED IN FINAL, FORM DECEMBER 8. 1994.

Reprint requests to: Dr. W.J. Becker, Department of Clinical Neurosciences, Calgary General Hospital, M6-012, 841 Centre Avenue E., Calgary. Alberta. Canada T2E 0A1 
condition, surgical sympathectomy can be successful if done early in the patient's course, although the use of sympathectomy in these patients has been challenged. ${ }^{3}$

There remain patients however, particularly those in whom therapy may not have been commenced early in the course of the disease, who become intractable with completely disabling limb pain and allodynia. Spinal cord stimulation has been recommended for such patients, but is often not successful.

We report here two patients with longstanding intractable RSD who obtained significant benefit from long term intrathecal morphine therapy. Although expensive, the side effects of this therapy over many years appears to be acceptable, and the benefits can be very substantial for these unfortunate individuals.

\section{MeThoDS}

We studied two patients who were treated with intrathecal morphine for intractable RSD. The disability experienced by each patient in relation to the various therapies used is summarized in Figures 1 and 2.

\section{Patient 1}

In May 1986, this 42-year-old female patient suffered a soft tissue injury to her right foot without fracture or skin breakage when it was crushed by a fire door during a fire drill. Within days she complained of increasing burning pain in the foot which spread slowly proximally with increased sweating and vasomotor change. She was treated with physiotherapy and analgesia and eventually was placed in a cast for seven weeks without resolution of symptoms. Her condition improved slightly in November 1986, but in January 1987, the foot and calf again became very swollen and painful and a diagnosis of reflex sympathetic dystrophy (RSD) was made. She was managed with physiotherapy, analgesia, and then guanethidine Bier blocks. None of these measures resulted in long term pain control, and the Bier blocks in fact aggravated her pain. She was unable to bear weight, and the swelling progressed up the leg to the level of the knee. On admission to hospital on April 26, 1987, her leg was very painful with diffuse burning pain restricted to the right leg below the knee. Her leg was markedly swollen, with shiny, red, mottled skin, and even the lightest touch elicited severe pain. The right foot was $5^{\circ} \mathrm{C}$ cooler than the left, with advanced trophic skin changes. Unsuccessful drug trials by this time had included high dose tricyclic drugs with perphenazine, carbamazepine and propranolol $(200 \mathrm{mg} / \mathrm{day})$. Several local anesthetic lumbar sympathetic blocks were done, including utilization of a continuous catheter technique. Each block markedly

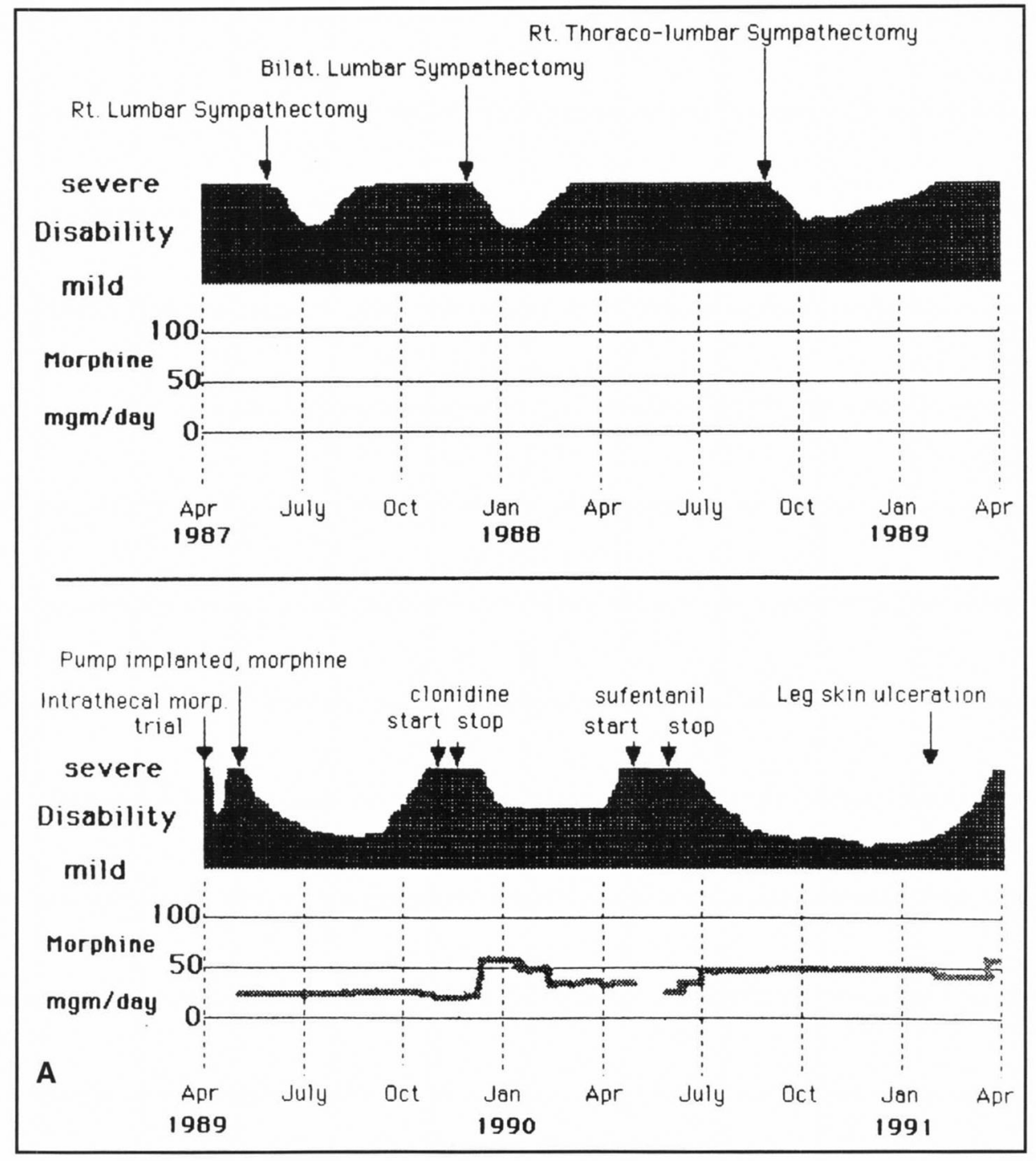

Figure 1: The clinical course of Patient 1 is summarized in $A$ and $B$, beginning when she came under our care a year after her foot injury. The approximate degree of disability is shown in diagramatic form, along with the dates of significant occurrences which seemed to influence disability. Disability was due primarily to severe buming leg pain, the inability to tolerate any sort of contact with the skin of the leg, and severe swelling. As a result. the patient was unable to walk for long periods of time. The ongoing daily intrathecal morphine dose is shown in the graph beneath the disability diagram. 
but transiently improved her symptoms. A right lumbar sympathectomy was done on June 5,1987 . The right leg improved dramatically, and physiotherapy was initiated. Five weeks after surgery however, her burning pain began to return. This was followed by increased swelling of the right leg and 10 weeks after surgery her leg was back to its preoperative status. An epidural stimulator was tried, but unhelpful. A port-a-cath was then inserted into the epidural space, and marcaine injections were given on a daily basis. These provided good pain relief, and physiotherapy was restarted. When the marcaine injections were discontinued however, the pain rapidly returned, and a further sympathectomy, this time involving a bilateral lumbar sympathectomy was done on December 8,1987 . Within a week, her leg showed marked improvement. Physiotherapy was again started, and she was gradually weaned off her oral morphine. The symptoms in her right leg began to relapse around March 7, 1988, and she was readmitted to hospital. X-rays showed gross demineralization of the right tibia and fibula and of the right foot. A bone scan showed hyperaemia in the right calf and right foot, and the delayed scan showed generalized increased uptake in this area, consistent with RSD. Continuous spinal anesthesia was instituted using a nylon catheter. As long as the level of sensory block was at T6 or below, the leg continued to be painful with allodynia. When the sensory level was at $\mathrm{T} 4$ or above, the pain and allodynia were abolished. She was given a six week course of high-dose steroids, but this provided no benefit. Eventually, on August 26, 1988, she had an extensive right thoracolumbar sympathectomy, with the sympathetic chain removed from the first rib to the L2 level. Within two days of surgery there was a dramatic improvement. Her morphine dosage was slowly reduced, and physiotherapy could again be initiated.

The patient did reasonably well as an out-patient until March 1989, when she had a severe exacerbation of her symptoms. The right leg again was severely swollen, and could not be touched. Deep venous thrombosis was ruled out by venography. On March 29, 1989, a intrathecal catheter was placed percutaneously, and an infusion of 12.5 milligrams per day of intrathecal morphine was given by continuous infusion for seven days. On day four of the infusion, the right leg began to feel better, and within two further days, there was a dramatic decrease in both pain and swelling. By the time the catheter was removed on the seventh day, the leg looked almost normal. Two weeks later however, the leg was as bad as ever, and a model 400 Infusaid infusion pump was implanted, with an intrathecal catheter. Her response to intrathecal morphine delivered by the pump was slow, but after several weeks, she was improving significantly. Her improvement continued rapidly, and she became virtually symptom free. She was able to travel to Europe and Asia and walk long distances. Her leg swelling had completely resolved. On September 20, 1989 she had a slight increase in her symptoms, and by October 14 , 1989 she was developing increasing pain and swelling. X-ray contrast injected into the pump side port showed the catheter system to be intact, with the contrast material entering the thoracic sub-arachnoid space at the level of T10. On October 31, 1989, she was readmitted to hospital as a recent increase in her morphine concentration to deliver $32 \mathrm{mg}$ per day into the intrathecal space had not resolved her symptoms. The leg was grossly swollen up to the mid-thigh, it was shiny and the slightest touch caused pain. Clonidine was added to the pump so that the pump delivered morphine $27 \mathrm{mg}$ per day, and clonidine $0.15 \mathrm{mg}$ per day, but there was no improvement. On November 10 the pump was refilled with morphine only, to deliver $33 \mathrm{mg}$ per day.

Her leg pain and swelling remained severe, until her morphine dose was increased to $55 \mathrm{mg}$ per day, on December 8, 1989. By December 18 she was able to walk well, but the right leg remained markedly swollen, discoloured and sensitive to touch. She did reasonably well then until April 15, 1990, when she was readmitted to hospital because of worsening of her leg pain. Her leg showed more severe swelling, discolouration, and allodynia. The pump was filled with sufentanil, in an attempt

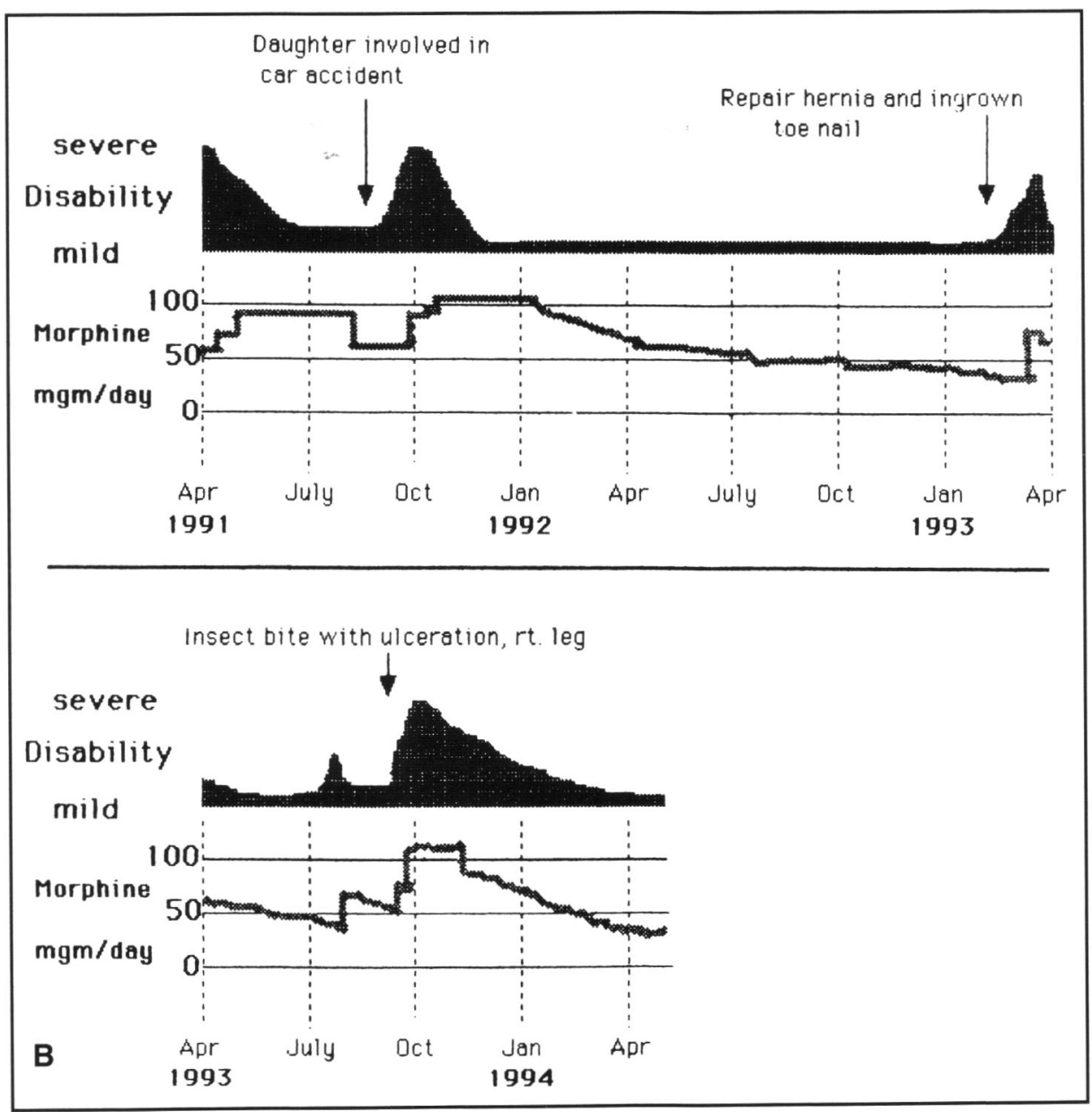

Figure 1: (continued). 
to reduce her tolerance of the morphine. She underwent morphine withdrawal symptoms and required parenteral morphine. The pain in her leg however remained intractable, and the pump was again filled with morphine. Hospital discharge was possible by July 3, 1990, at which time her pump was delivering $50 \mathrm{mg}$ of morphine per day, and she was off all additional oral and parenteral morphine, and was started again on physiotherapy. While in hospital, capsaicin cream was tried on her leg for a number of weeks without any success. During this admission, a CT scan of the lumbosacral spine, and also of the lumbosacral plexus showed no abnormality.

The patient did well, and on August 1990 she was mobile, had reduced leg swelling and was very active at home. On January 21 , 1991, she showed irritation of the skin over the front of her right leg, with redness but no obvious skin breaks. By February 19, 1991, she had three small ulcers over the anterior surface of the right leg, and her pain had been slowly increasing for several weeks. On March 16, 1991, she was readmitted to hospital with a markedly swollen, discoloured, painful and hypersensitive leg. The skin was ulcerated over her anterior leg, and she was felt to have a cellulitis. These ulcerations oozed considerably, and she received antibiotic therapy. Her morphine dosage was increased to $85 \mathrm{mg}$ of morphine per day delivered intrathecally, and she began to improve rapidly. Initially her swelling went to just below her hip, and this had descended to just above the knee by May 8,1991 . Her leg became warm, there was much less allodynia, and she could now once again elevate her leg, something she had been unable to do previously because of unbearable pain.

On October 2, 1991, she was again admitted to hospital with a flare of her RSD. No precipitants were obvious, except that her morphine dosage was being gradually reduced, and also she had considerable emotional stress because her daughter had recently been involved in a car accident. She again required parenteral morphine to control her pain. Her pump morphine concentration was increased to deliver $109 \mathrm{mg}$ of morphine daily, and her leg began to improve. During this hospitalization, the patient had also developed swelling of her left leg which involved primarily the foot, but the leg left was never a major problem in terms of pain. By discharge on November 22, 1991, she had gone from a bed-ridden state to being able to walk again using her leg brace. Her right leg was still swollen and reddened, and she still had some burning pain, but required only occasional oral analgesics in addition to the intrathecal morphine. She did well until March 1993 when she had an incisional hernia repaired and surgery on a right ingrown toenail. Four days post-operatively she had an increase in pain and swelling of the right leg. Her intrathecal morphine was rapidly increased from 36 to $74 \mathrm{mg}$ of morphine per day, and her symptoms rapidly subsided.

The patient then did well until September 1993, when she developed a cellulitis of the right leg secondary to an insect bite on the

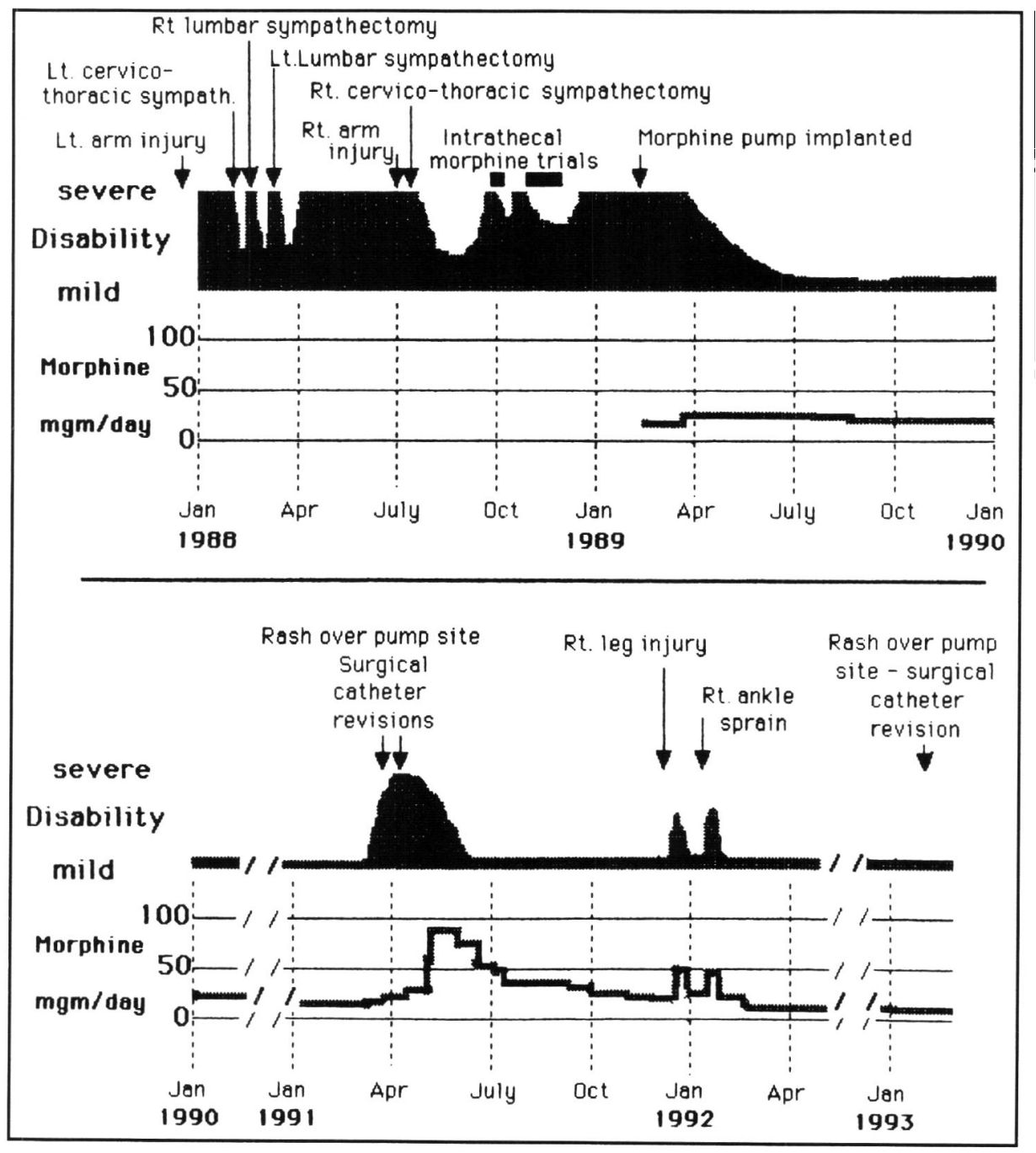

Figure 2: The clinical course of Patient 2 is summarized in a similar manner as described under Figure 1 for Patient 1 . Note the time breaks in the lower panel, which were used to reduce the size of the figure. During these relatively long periods, the level of disability was minimal and stable, with no exacerbations of the RSD. 
shin. The area of the bite developed a small ulceration. By September 15, 1993, she was developing increasing foot and lower leg swelling and was becoming sensitive to mechanical stimuli again. Her intrathecal morphine dosage was increased, but she failed to improve so that on September 23, 1993, her pump was refilled to deliver $109 \mathrm{mg}$ per day of morphine, the maximum rate possible. On September 28, 1993, it was necessary to admit her to hospital, because her leg again was very swollen, and she had extreme pain. She spent her nights sitting in a cardiac chair, because she could not bear to lie down. On the advice of our infectious disease service, she was once again given parenteral antibiotics. She also again required intravenous morphine. By October 7, 1993, her pain was clearly improving, although her leg was still swollen, including some swelling with marked induration extending for 10 inches above the knee. Her allodynia was subsiding, and her leg continued to improve steadily. On follow-up in January 1994, all leg swelling was gone, and her right leg was smaller than the left. She was free of leg pain and, as before, driving, shopping and running her household independently. In April 1994 she remained well.

\section{Patient 2}

In 1975 at the age of 14 , this female patient injured her right knee while playing baseball. A week later her leg became swollen and painful for a one week period. Thereafter she had recurrent remissions and exacerbations with burning diffuse pain, swelling, coldness and cyanosis involving the right leg. Initially a diagnosis of venous insufficiency was made, and she was treated for several years with subcutaneous heparin by self-injection, although three venograms were negative. A bone scan in 1984 showed increased uptake of radioisotope in the right foot and leg. On December 5, 1987 while working as a respiratory technologist, a confused patient squeezed her left arm while she was taking a blood gas. Although there was no fracture, skin break, or other overt sign of injury, three days later her arm became swollen, cyanotic, and she developed diffuse burning pain. Her symptoms were severe enough that the wrist was splinted and a cast was eventually applied. A bone scan showed increased radioisotope uptake in the left arm and right leg. Reflex sympathetic dystrophy (RSD) was diagnosed. Repeated stellate ganglion blocks produced only brief relief. Her pain would subside for only $2-3$ hours with $12 \mathrm{mls}$ of $0.25 \%$ Marcaine with $1 / 200,000$ adrenaline (normally one would expect a duration of action of 8-10 hours). Intermittent and then continuous brachial plexus blocks via the supraclavicular route provided good pain relief, but pain always returned as the anesthetic wore off. The problem with her left arm did not permanently resolve and she eventually underwent a left cervicothoracic (C7-T4) sympathectomy on January 29, 1988. This provided excellent relief, but five days post-operatively she had a recurrence of the pain in her right leg. Right leg symptoms had been relatively quiescent for two years prior to this. The leg became swollen, had more allodynia, and did not respond to numerous therapies including lumbar epidural anesthesia, intravenous narcotics, nifedipine, and beta blockers. A right lumbar sympathetic block produced marked but temporary pain relief. She eventually underwent a right lumbar (L1-L5) sympathectomy on February 13, 1988, and had two weeks of good relief. The symptoms in her right leg then recurred, and she underwent a left lumbar sympathectomy on March 6, 1988, with the L1 to L5 sympathetic ganglia removed. Once again her right leg symptoms improved temporarily, but after four weeks, the right leg problem recurred. Further medical therapy was tried with guanethidine, clonidine, and high dose indomethacin. None of these were successful, but the right leg did respond to intravenous guanethidine regional anesthesia (Bier block) with relief for about ten days. Numerous guanethidine blocks were then used as symptomatic therapy, but eventually these became less effective in producing symptomatic relief. High-dose steroid therapy including methylprednisolone was not helpful. On examination during these exacerbations, the calf diameter of the left leg was $15 \mathrm{~cm}$, that of the right leg $21 \mathrm{~cm}$. In addition to the swelling, the right leg showed shiny, atrophic skin, with extreme pain on the slightest touch. In May 1988, swelling and pain was also noted in the left leg, but this was less severe and resolved after several weeks.

Subsequently, other medical therapies were tried including phenoxybenzamine $(150 \mathrm{mg} /$ day $)$, calcitonin injections and prazosin $(6 \mathrm{mg} /$ day $)$. In July 1988 she slipped in the bathtub, suffering a mild injury to the right arm. Swelling followed, along with diffuse pain. She underwent a right cervico-thoracic (C7-T4) sympathectomy on July 17, 1988 which immediately relieved her symptoms in the right arm and also temporarily improved her symptoms in her right leg. However her right leg relapsed again with severe symptoms two months later.

Although her sympathectomies proved effective for her problems in her arms, the right leg remained a very serious and disabling problem. with pain, swelling, and allodynia. She was admitted to ICU where continuous epidural anesthesia was instituted utilizing marcaine $0.5 \%$ to produce a level of sensory and motor block to approximately T8. Despite this, she continued to have pain and allodynia in the right leg and required large doses of parenteral morphine and diazepam. Massive edema of the whole leg was a problem, and she started to develop a cellulitis. General anesthesia was instituted for three days with good resolution of symptoms, but these recurred after a few days. Continuous spinal anesthesia utilizing a $20 \mathrm{~g}$ nylon spinal catheter was instituted, producing a level of sensory and motor block to T4 with resolution of symptoms, but pain remained a problem if analgesia was at T6 or below. On October 3, 1988, a percutaneous intrathecal catheter was placed, and morphine $9 \mathrm{mg}$ per day was found to produce a dramatic decrease in the pain and swelling of the right leg. Sufentanil and Fentanyl were not helpful. After four days of morphine therapy, her leg was much better, with the leg changing from cold to warm, and with a dramatic decrease in pain and swelling. After six days, the infusion was stopped, and five days later her leg again began to deteriorate. A port-acath with an intrathecal catheter was then implanted on October 21 , 1988, and she received morphine $3 \mathrm{mg}$ three times a day by injection for four days with little benefit. Nine milligrams $(9 \mathrm{mg})$ of morphine per day by constant infusion was then started, and the pain decreased dramatically over two days. After four days of continuous infusion, intermittent injections were again started, and the improvement continued. However, 22 days after placement of the port-a-cath, it had to be removed because of the development of bacterial meningitis, despite good progress in the control of her RSD. After the port-a-cath was removed, improvement in her RSD lasted a further three weeks, but then her leg gradually deteriorated again.

On February 8, 1989, an Infusaid Model 400 infusion pump was implanted, with an intrathecal catheter. Initially $12 \mathrm{mg}$ of morphine per day produced little improvement. After the morphine concentration was increased to deliver $25 \mathrm{mg}$ per day, improvement was noted after several days. Prior to implantation of the pump, her right leg was severely involved, and after implantation, symptoms progressed to involve the left leg also in a severe fashion, before improvement eventually began.

The patient improved dramatically, and by July 1989 was able to go hiking for long distances in the Rocky Mountains. By October 1989 she was working part-time as an administrator, and by July 1990 was able to travel across the country on holidays.

She was working full-time as a respiratory technologist and was able to play volleyball for recreation when in March 1991, she found that she could not shower anymore because the water was painful on her leg. Her leg became tender to touch, and swollen. She noted a red rash over the pump site, and this increased in severity. The leg did not improve with increased concentrations of morphine in the pump, and she developed headache and nausea. X-ray contrast injections were made on March 20, 1991 into the pump side port, and these showed a leak in the catheter in the area of her back. On March 21, 1991, her pump catheter was repaired surgically, and at surgery several small holes in the catheter were found. A week later, at discharge, the rash over her pump site was greatly improved, but the leg had not improved. By April 11, 1991, the leg had not improved and a repeat contrast injection into the pump side port showed continued leakage. so the entire catheter system was replaced surgically. After this procedure, her right leg still did not improve, and her left leg also became involved. As had happened during previous severe exacerbations, she developed huge blebs over the dorsum of her feet which would rupture and leak serous fluid as she sat semi-upright in a dazed condition because of drugs and pain. Both legs showed massive edema. When the pump morphine concentration was increased to deliver $88 \mathrm{mg}$ per day, her legs began to improve and eventually returned to normal.

In December 1991, she had no symptoms, and was active in sports. While playing volleyball, she injured her right leg. The leg became hypersensitive to touch, painful and began to swell. Her morphine 
dosage was increased from $23 \mathrm{mg}$ per day to $50 \mathrm{mg}$ per day. She did very well, and in January 1992 was on a $20 \mathrm{~km}$ hike in the Rockies, when she slipped, sprained her right ankle, and was unable to bear weight. There was no fracture, but her leg began to swell diffusely, her skin became very hypersensitive, and once again her morphine concentration was increased, this time from 26 to $50 \mathrm{mg}$ per day. Her leg improved again and she was able to continue working full time and play baseball. She considered herself asymptomatic.

On January 27,1993 , a rash was noted over her pump site. She developed a headache compatible with a low pressure headache. The rash was felt to once again be due to morphine extravasation into subcutaneous tissues from a catheter leak. Contrast injections were done into her pump side port, but $x$-rays could not demonstrate a leak, and the dye entered the intrathecal space as expected. Technetium radio-isotope injections were also done, but gamma camera and Spect imaging could not reveal a leak.

The patient's catheter system was surgically explored on January 30 , 1993, the catheter connections were explored, but a leak could not be demonstrated at surgery. However, her headache and nausea rapidly resolved, and the rash over the pump site faded. During this episode, her RSD did not exacerbate, and she was discharged from hospital, and continued working full time. In December 1993, the patient remained well and was working full time as a respiratory technologist. Her intrathecal morphine dosage was $7 \mathrm{mg} / \mathrm{day}$, and was being slowly reduced.

\section{Discussion}

The extreme suffering and disability experienced by these two patients cannot be over emphasized. When their RSD was active, both patients had massively swollen legs with remarkable induration which could not be touched without eliciting severe pain. Worse than being confined to a hospital bed, these patients could not lie flat because elevation of the leg in any way exacerbated the pain.

Our patients did respond to some extent to regional sympathetic blocks, and as a result surgical sympathectomies were done. It is of great interest that in Patient 2, on both occasions, the arm symptoms which had developed relatively recently before the sympathectomies were done responded quickly and apparently permanently to the sympathectomies. However, in both patients, the RSD in the legs responded only transiently to surgical sympathectomy. It must be kept in mind however, that in both patients the RSD in the legs had begun more than a year before the sympathectomies were done.

Intrathecal morphine has been reported to be effective in the treatment of intractable RSD, ${ }^{4.5}$ although there are few published reports. In both patients, intractable massive leg swelling and pain which had not responded in a long term fashion to surgical sympathectomy was eventually brought under good control through the use of continuous intrathecal morphine therapy. This control was likely unnecessarily delayed in both patients through the use of an inadequate dose of morphine initially, especially in Patient 1. In both patients, it was ultimately found that rapid escalation of the intrathecal morphine dose to dosages approaching $100 \mathrm{mg} /$ day could relatively rapidly abort exacerbations of their RSD. Gradual tapering of this dosage could then be achieved, although Patient 1 appeared to require higher baseline dosages than Patient 2.

It is of interest that our patients continued to have exacerbations of their RSD, usually apparently in response to physical trauma, even once control of the RSD with morphine had been largely achieved. In Patient 1, skin ulcerations over the anterior leg, some apparently in response to insect bites, appeared to trigger relapses. It is possible that the sores and skin ulcerations which would gradually heal were related to the RSD itself. In this patient, however, at least one exacerbation was caused by a hernia repair done in association with removal of an ingrown toenail after a period of over one year during which time the patient's RSD had been quiescent on morphine therapy. In Patient 2, the relationship between physical trauma and exacerbation of the RSD was even more striking. On two occasions, this patient went from a quiescent state on morphine therapy to a marked exacerbation of the RSD in the leg in response to a relatively minor right leg injury obtained during participation in sporting activities. In cases where the RSD exacerbation was clearly linked to a physical trauma, rapid escalation of the morphine dosage invariably quickly brought the RSD back under control. Although it might be argued that we were simply observing the natural history of the disorder, these exacerbations terminated by the increased morphine dosage seemed to be much shorter in duration than other exacerbations the patients had experienced in the past. The exacerbations related to apparent skin ulcerations in Patient I proved more difficult to control, and were more prolonged. These exacerbations may also have been related to reductions in the morphine dosage, as we were continually attempting to gradually reduce the morphine dosage to achieve the lowest necessary drug administration level. Finally, the exacerbations associated with skin ulceration may also have been maintained in part by infections, as our infectious diseases service did diagnose leg cellulitis on both occasions in Patient 1 . However, this was a very difficult diagnosis to make given the extreme leg swelling and redness associated with the RSD itself during these exacerbations.

Several lessons were learned during our experience with long term intrathecal morphine therapy of RSD. Firstly, when an exacerbation of the RSD began, whether in response to recognized leg trauma or not, rapid escalation of the morphine dosage to, if necessary, $100 \mathrm{mg} / \mathrm{day}$, was essential to abort the exacerbation as quickly as possible. It was important for patients to report these exacerbations at the earliest possible time to the treatment team. Secondly, a red rash appearing over the pump site may be the first indication that a catheter breakage has occurred. This rash presumably occurs as a result of histamine release in the skin by the extravasated morphine, and is an indication that the treatment team must evaluate the integrity of the catheter as quickly as possible, and repair it before an exacerbation of the RSD occurs. Under these circumstances, the surgery associated with catheter exploration and repair does not necessarily result in an exacerbation of the RSD if done quickly while the RSD is still under control. Thirdly, at least in our patients, addiction to the morphine delivered intrathecally (or intravenously while hospitalized) was in no way a problem. In fact, both our patients were constantly pressuring us to reduce the intrathecal morphine dosage as quickly as possible. At high doses, both patients, and in particular Patient 2, noted tolerable but significant side effects of nausea and feeling generally unwell. These side effects would disappear as the dosage was reduced.

RSD may well be a heterogenous condition, and our two patients with their long term massive leg swelling, pain and allodynia, may well not be typical of the average patient with RSD. It is also possible that the long term intrathecal morphine and/or sympathectomies may have modified the natural history of the RSD. However, it is noteworthy that the severe arm symptoms in 
Patient 2 both responded apparently permanently to early sympathectomy, whereas the intractable right leg symptoms which had been present for a much longer period of time did not respond to sympathectomy. This may reflect a difference between the arm and the leg in terms of response to sympathectomy, or may be the result of the longer duration of the disease in the leg.

We can draw few conclusions with regard to pathophysiology, with the exception of some of the observations noted above. It is however of extreme interest that in both patients, when they were in the intensive care unit, the sensory block from spinal anesthesia had to be maintained at the T4 level to abolish the pain and allodynia in the lower extremity. Even a block as high as the T6 level was not sufficient to abolish the pain. This would suggest that nerve fibres entering the spinal cord at levels as high as the T5 and T6 levels were capable of mediating some of the dysaesthetic pain from the leg experienced by these patients. The neuronal pathway involved is unknown, but could involve autonomic afferent fibres from the legs running to higher levels in the sympathetic chains or in the perivascular including periaortic nerve fibres. The sympathetic ganglia had been removed in our patients, but incomplete removal or regeneration cannot be ruled out.

The pathophysiology of RSD remains unknown. Prominent in current theories are the concepts that peptide release from afferent nociceptor nerve endings may be important in causation of the tissue swelling and pain, that altered sympathetic outflow to the limb may sensitize both mechanoreceptors and nociceptors, and that derangements might take place in the spinal cord dorsal horn in response to abnormal peripheral inputs which could result in a greater response to nociceptive inputs or in mechanoreceptor inputs being perceived as painful. ${ }^{2,6-9}$ How the intrathecal morphine might interrupt the pathophysiology to allow resolution of the pain, the allodynia, the swelling, and the abnormally reduced temperature of the limb is unknown. Opioid receptors are present in the dorsal horn both on primary afferent fibres and on intrinsic spinal neurons including neurons in the substantia gelatinosa and on the spinothalamic tract cells. ${ }^{10}$ While these receptors might be relevant in the treatment of RSD by intrathecal morphine, morphine also has many other effects which might be equally important. It does seem likely, however, that opiate alkaloids can modulate nociceptive transmission at the level of the primary afferent synapse between the nociceptive afferent fibre and the dorsal horn projection neuron by a combination of presynaptic and post-synaptic actions.

In summary, intrathecal morphine in the appropriate doses appeared capable of controlling intractable RSD in both our patients. Exacerbations of RSD in response to physical trauma and other factors perhaps including reduction in morphine dose continued to occur, but could usually be rapidly brought under control by temporarily increasing the morphine dosage. Side effects from this therapy were relatively minimal, with no pump, catheter, or central nervous system infections. Catheter breakage however can result in a rapid recurrence of the RSD in these patients, necessitating surgical catheter repair.

\section{REFERENCES}

1. International Association for the Study of Pain. Classification of Chronic Pain: Description of Chronic Pain Syndromes and Definitions of Pain Terms. Prepared by a Sub-Committee on Taxonomy. Pain, Suppl. 3, 1986.

2. Kozin F. Reflex sympathetic dystrophy syndrome: a review. Clin Exp Rheumatol 1992; 10: 401-409.

3. Ochoa JL. Guest editorial. Essence, investigation, and management of "neuropathic" pains: hopes from acknowledgement of chaos. Muscle Nerve 1993; 16: 997-1008.

4. Goodman RR, Brisman R. Treatment of lower extremity reflex sympathetic dystrophy with continuous intrathecal morphine infusion. Proceedings of the meeting of the American Society for Stereotactic and Functional Neurosurgery. Montreal, Appl Neurophysiol 1987; 50: 425-426.

5. Hooshmand $\mathbf{H}$. Chronic pain: reflex sympathetic dystrophy, prevention and management. CRC Press, Boca Raton, USA, 1993: 160161 .

6. Marchettini P, Lacerenza M, Ieracitano D, Canal N. Sensitized nociceptors in reflex sympathetic dystrophy. Funct Neurol 1989; 4: $135-140$.

7. Cline MA, Ochoa J, Torebjork E. Chronic hyperalgesia and skin warming caused by sensitized $C$ nociceptors. Brain 1989; 112: 621-647.

8. Dray A, Perkins M. Bradykinin and inflammatory pain. Trends Neurosci 1993; 16: 99-100.

9. Dubner R, Ruda MA. Activity-dependent neuronal plasticity following tissue injury and inflammation. Trends Neurosci 1992; 15: $96-102$.

10. Mortin CR, Hutchison WD, Duggan AW, Hendry IA. Morphine and substance $P$ release in the spinal cord. Exp Brain Res 1990; 82: 89-96. 